\title{
Platero, R. Lucas; Rosón, Maria y Ortega, Esther (Eds.) (2017): Barbarismos queer y otras esdrújulas. Barcelona: Edicions Bellaterra. 432 pp. ISBN: 9788472908291.
}

La palabra queer o cuir -en su uso más hispano- no es únicamente un término. Detrás de su significado insultante, pues queer, para los angloparlantes puede seguir siendo un insulto a proferir contra personas LGTB y, como bien reza el título de la obra sobre la que versa esta reseña, otras esdrújulas.

Lo queer ha estado sumido en el imperio de lo incomprendido, no sólo por la sociedad, sino que también por la ortodoxia académica, universitaria y científica, sin olvidar a algunas líneas y tendencias teoréticas en los feminismos.

Sopa de letras, tal y como lo define Lucas Platero, uno de los editores de esta obra colectiva, que desde este texto se pretende ilustrar, de manera tal que quien lee este libro termina comprendiendo, no sólo lo qué es lo queer, sino planteándose muchas preguntas con respuestas sobre la comprensión y la inmensidad que es la diversidad sexo/genérica.

Barbarismos queer y otras esdrújulas, es una obra colectiva, editada por R. Lucas Platero, María Rosón y Esther Ortega en la Editorial Bellaterra. El elenco de autores y autoras que desarrollan cada uno de "los barbarismos", a modo de definiciones, son un valor añadido de gran riqueza social, científica y vital, pues hacen de este libro un punto de encuentro entre diferentes visiones $\mathrm{y}$ formas del ser $\mathrm{y}$ estar queer.

Barbarismos queer permite entender y utilizar correctamente palabras -identificados en la obra como palabros y barbarismos- que han nacido en el seno del activismo, los estudios postfeministas y los estudios sobre sexualidad e identidad de género. Pero desde posiciones al margen de la ortodoxia académica y subalternas.

La mayoría de los conceptos y términos contenidos en Barbarismos queer son, como indica la esclarecedora introducción esdrújulas, otro término que es sacado de su contexto y deslocalizado en cuanto a su significado. Una estrategia audaz para tratar el contexto que hace que lo queer sea queer.

Un viaje a través de palabras e idiomas que recorren toda la teoría derivada de las multiplicidades del ser y estar en un género /sexo /sexualidad /cuerpo abierto. Lo queer y los barbarismos que acompañan son abiertos, cambiantes y descontextualizables. Cada uno de esos términos responden, no sólo al trabajo de ilustrar de qué se compone lo queer, o qué es lo que le rodea. Sino que responden a los movimientos sociales y las teorías críticas inherentes a ellos.

Es una obra que nos sitúa histórica y socialmente ante procesos y momentos en cambio y transición vitales para comprender la sexualidad, el género y el cuerpo en la contemporaneidad de lo subalterno, de limítrofe y lo plural. La diversidad.
Las esdrújulas, referidas anteriormente y que van componiendo este mosaico teórico, es una manera reinventada en cuanto a su significado y etimología. Son palabros complejos cuyo uso está íntimamente unido a los movimientos sociales, los contextos académicos o artísticos que los recorren.

Uno de los tesoros teóricos y sociales que guarda esta obra es la referencia a lo queer desde diferentes ópticas, matices y autorías, con el fin de desentrañar de una vez por todas -sobre todo para los neófitos en materia- qué es lo queer. Por un lado, nos da la definición más amplia y difundida "una perspectiva crítica con respecto a la sexualidad, pero al tiempo entretegidas con otras experiencias que organizan nuestras vidas y que exceden las experiencias sexuales o de género" (p.12). Y por otro lado nos confirma las sospechas lógicas sobre lo queer, no parte de una experiencia global y única, pues no es una lógica impositiva y de imitación obligatoria.

Barbarismos queer y otras esdrújulas se compone de 53 palabros, barbarismos y esdrújulas a modo de entradas de múltiple autoría, lo cual enriquece aún más el recorrido por lo queer.

El primer término es el de "agencia" desarrollado por Virginia Villaplana Ruiz; seguido del palabro "Armario Closet" escrito por Nuria CapdevillaArgüelles, entrada que desambigua el palabro closet; el siguiente barbarismo es "Bareback" definido por Javier Sáez; BDSM o sadomasoquismo definido por Miguel Vagalme; Cristina Mateos Casado es la encargada de detallar la siguiente "esdrújula" que no es otra que "Binarismo"; "Buch/Femme" es una de las entradas -como si de un diccionario se tratara la obradefinida por Carmen Romero Bachiller y R. Lucas Platero; "Camp" es la otra esdrújula explicada por Jordi Costa; Mario Toboso Martín es el autor de "Capacitismo / Ableism; El barbarismo "Cis" está firmado por Antar Martínez-Guzmán; Silvia Nanclares se encarga de exponer el palabro "Cognitariado"; Crianza queer/ Cuir es una de las entradas más actuales cuya autoría corresponde a Fefa Vila Núñez; Robert McRuer se encarga de aproximarnos al barbarismo "Crip"; Melania Moscoso-Pérez autora de "Cripwashing" nos ayuda a comprender un barbarismo de gran calado social como es la instrumentalización de los derechos humanos en personas con discapacidad.

R. Marcos Mota nos introduce a la compresión del barbarismo "Cross-dresser" muy desconocido entre las personas ajenas a las líneas teóricas cercanas a lo queer $\mathrm{o}$ alejadas a los estilos de vida de la diversidad del ser sexo/genéricamente no normativos. 
El barbarismo "Cruising" corre a cargo de José Antonio Langarita Adiego; "Cyborg" es el siguiente barbarismo, un término muy bien acogido en las teorías feministas desde los años 80 , pero poco comprendido y que es muy bien explicado, desde un punto de vista teórico y práctico en esta entrada cuya autoría corresponde a Carme Adán.

Despatologizando, palabro desarrollado por Amets Suess Schwend, término vital en el desarrollo de los derechos de los colectivos no heterocentricos.

O.R.G.I.A (Beatriz Higón, Carmen Muriana y Tatiana Sentamas) son las encargadas de definir y explicar el barbarismo y esdrújula "Dildo o Disfrutador". Su texto más que esclarecedor tiene un matiz importante como acto reivindicativo/político.

"Embobiment / embodimén" es uno de los barbarismos que tiene esa doble designación que hace de lo queer algo lejano a la inmanencia y estatismo. En el caso que nos ocupa este texto explicativo corre a cargo de Meri Torras Francés.

Silvia López Rodríguez introduce el ya más que reiterado término, otrora barbarismo, "Empoderamiento", aclarando su origen, cómo y para quienes debe dirigirse; "Enactment" es el siguiente barbarismo y palabro firmado por Rebeca Ibáñez Matín, término por una mayoría desconocido, pero de vital importancia a la hora de entender e investigar las diversidades del ser y estar en un sexo/género/cuerpo.

"Ensamblaje" sería un palabro y una esdrújula de lo queer, entrada que corre a cargo de Nuria Sadurní Balcells; O.R.G.I.A (Beatriz Higón, Carmen Muriana y Tatiana Sentamas) incluyen el barbarismo "Fisting"; Brice Chamouleau hace la entrada del barbarismo "Gay" desde una perspectiva real e innovadora, la realidad de la homonormatividad y la innovación de tratar el significado político de este término en perspectiva postcolonial. "Gordofobia", palabra que viene a ser más un palabro que un barbarismo, es una de las más comunes de todas las palabras que componen este texto, sea por la subversión como moda social por incluir a todos los cuerpos como cuerpos, sin normatividad ni reglas estéticas que valgan, en esta obra es definida por Lucrecia Masson; Ana Pol y María Rosón firman la definición del barbarismo "Haunted"; Javier Saez y José Ignacio Pichardo se encargan del palabro "Heterofuturabilidad" un término cuanto menos sugerente pues nos hace pensar en posibles futuros en lo que a estilos de vida y del ser sexo/genéricamente hablando nos puede deparar, futuros inquietos o futuros abiertos.

El palabro y esdrújula "Heteronormatividad" correa a cargo de Miguel Ángel López Saez. Su "entrada/capítulo" es una referencia desde lo personal, desde lo que política y culturalmente significa. Diego Fraile Gómez es el autor de la entrada "Homoerotismo, un término conocido pero un intruso en la ortodoxia de las teorías de género de gran importancia y necesario esclarecimiento.

La entrada a "Homonacionalismo" está realizada por Jokin Azpiazu Carballo quien de manera clara y concisa nos introduce en un término de alto impacto político a nivel global. Continuadamente se incorpora el palabro "Homonormatividad" esdrújula escrita por Enrique Latorre Ruiz y Jokin Azpiazu Carballo. Continuando ilustrando a los lectores en palabros de gran carga política y social.

R. Lucas Platero se hace cargo de la entrada "Interseccionalidad", un palabro que nos hace pensar cuantos recorridos socio-culturales y políticos tiene la interseccionalidad en lo que se refiere a la opresión social de las no normatividades. "Intersexualidades" precede a la entrada de "interseccionalidad" haciendo un perfecto correlato entre dos palabros y esdrújulas que son necesarias de comprenderse de manera seguida, aunque en este caso haya sido el azar de un "orden" alfabético. Esta entrada es firmada por Dau García Dauder y Nuria Georgi Flor, un término que nace en la clínica obstetricia, más bien en la quirúrgica en casos extremos y que en la actualidad la intersexualidad moderna incluye características psicológicas, sociales y mágicas. Aunque las ramas que han invadido este palabro hayan sido las de la religión, el derecho y la medicina.

El palabro "Islamofobia" cuya autora es Brigitte Vasallo, trata un tema social de vital importancia en la contemporaneidad, pero desde las perspectivas de género y sexualidad. Gloria Fortún firma la entrada y barbarismo "Mawsplaining" a esta suerte de "sopa de letras" me evoca a la obra de "los hombres me explican cosas" de Rebecca Solnit, la diferencia entre los textos es que el presente hace una inmersión en la realidad de la sociedad del Estado Nación Español.

Diego Marchante genderhacker nos ilustra con la entrada "Masculinidad femenina" esdrújula de lectura obligada si es que pretendes inmiscuirte en los trabajos, estudios y estrategias político-artísticas de lo queer. "Memes" es el barbarismo que nos ilustra Amparo Lasén Díaz, una esdrújula que podría andar suelta, sin tener relación alguna con lo aquí abordado, pero que posee una intensa relación con los debates que el resto de barbarismos, palabros y demás esdrújulas nos exponen. El "meme" en perspectiva queer y feminista toma un protagonismo político y subalterno.

"Oso" esdrújula y palabro, puesto que no se están refiriendo al plantígrado sino a formas y estilos de vida de personas homosexuales, es una de las entradas más necesaria para romper mitos y estereotipos, firmada por Andrés Serna, describe la historia del origen de este estilo del ser y del vivir la homosexualidad, con un guiño a la subversión y a la lucha social y política.

Laura Corcuera González de Garay es la encargada del barbarismo "Outing", barbarismo y palabro que podría confundirse con salir del closet, la autora de esta entrada nos hace una correcta definición de las acepciones y sus consecuencias políticas del "Outing".

El barbarismo "Passing" definido por Nagore García Fernández es una entrada que define y conceptualiza de manera esclarecedora su uso y significado, social, político y corporal en perspectiva queer. Quizás sea este uno de las definiciones más 
necesaria de descubrir, sobre todo por su escaso uso en los espacios científico-académicos.

Iñaki Estella firma la entrada del concepto barbarismo "Performatividad", añadiendo luz a la performatividad en Butler desde un aspecto crítico y político-social.

"Prision-industrial complex" (Complejo industrial penitenciario, acrónimo PIC" de María Enguix. Puede parecer una entrada para los no conocedores de las teorías y trayectorias queer completamente ajena, por el contrario, esta entrada es una de las más sociales y políticas, sobre todo en materia de exclusión y capitalización.

Gema Pérez-Sánchez, nos remite al barbarismo "Pinkwashing", un barbarismo y esdrújula que está tomando fuerza y que se refiere a las prácticas nacidas desde la política estamental y sus derivaciones en la política crítica social.

Francisco Godoy Vega firma la entrada del palabro "Postcolonial". Concepto que es explicado desde las encrucijadas queer. "post porno" barbarismo-palabro que a su vez es esdrújula de lo queer y que en esta obra colectiva es definido y explicado por Lucía Egaña Rojas.

Pol Galofre Molero es el encargado de incluir la entrada de la esdrújula "Prótesis"-vuelvo a señalar que esta reseña no toma a esta obra como un compendio de términos sino, como un diccionario-sopa de letras de lo queer-. Ampliaciones de nuestros cuerpos que otrora fueron socialmente generizados y que pueden mutar, ampliarse o resignificarse con las técnicas y tecnologías políticas de las prótesis.

Javier Sáez tiene el honor de incluir el barbarismo "queer". La definición, historia y discurso que entreteje para describir este concepto sobre el que gira toda la obra, permite que todos y cada uno de los textos incluidos tengan un sentido político, social y científico.

"Slut-shaming" barbarismo de fuerte contenido político y denigratorio, sobre todo teniendo en cuenta que significa "tildar de puta o guarra" (P:389) se va convirtiendo en una estrategia de lucha $y$ resignificación de la libertad y apoderación de las personas. La autora de esta bocanada de aire fresco a los postfenismos de salón viene de la mano de Miren Elorduy Cádiz.

Noelia Igareda González autora de la entrada "Subrogación de la maternidad", un fenómeno con multiplicidad de nombres, de detractores/as y defensores/as y que en estos momentos en el Estado Nación Español es un tema de arduo debate entre los grupos feministas y la sociedad civil.

"TERF, Feminismo Radical Trans Excluyente" esdrújula y palabro expuesto por Raquel Osborne de manera magistral nos expone uno de los problemas que en los feminismos se da, pero no se cuenta. La exclusión de determinados colectivos y tipos de feminismos y formas del ser género/sexo por parte de grupos feministas o por parte del Feminismo Radical.

R. Lucas Platero hace la entrada de "Trans* (con asterisco). Una entrada necesaria y completamente significativa para dar forma a lo queer.

Para cerrar la obra nos encontramos con las entradas y esdrújulas "transfeminismo" definida por Sandra Fernández-Garrido y Aitzole Araneta y el de "Vientres de alquiler", términos conexos, difieren del concepto de "Subrogación de la maternidad". Esta entrada a modo de broche final es firmada por Gloria Fortín.

Barbarismos queer y otras esdrújulas es un texto de necesaria lectura para comprender y saber las resignificaciones que en la sociedad están dándose, de manera sociopolítica y no excluyente. Un mosaico en el que todas las piezas desencajadas encajan.

Jhonatthan Maldonado Ramírez Benemérita Universidad Autónoma de Puebla

México jhona.maldonado@gmail.com Recibida: 10-09-2017 Aceptada: 29-9-2017 